\title{
Rebranding Barokah Furniture Blitar Melalui Pelatihan Pemasaran di Sosial Media
}

\author{
Blitar Barokah Furniture Rebranding Through Marketing Training on Social Media
}

\author{
Harliana $^{1}$, Hartatik ${ }^{2}$, Raden Mohamad Herdian Bhakti ${ }^{3}$ \\ ${ }^{1}$ Program Studi Ilmu Komputer, Fakultas Eksakta, Universitas Nahdlatul Ulama Blitar, Indonesia \\ ${ }^{2}$ Program Studi Manajemen Informatika, Fakultas Computer Science, Universitas AMIKOM Yogyakarta, \\ Indonesia \\ ${ }^{3}$ Program Studi Teknik Informatika, Fakultas Teknik, Universitas Muhadi Setiabudi, Brebes, Indonesia \\ e-mail: ${ }^{1}$ harliana@unublitar.ac.id, ${ }^{2}$ hartatik@amikom.ac.id, ${ }^{3}$ bhakti@umus.ac.id
}

\begin{abstract}
Abstrak
Barokah meuble Blitar merupakan salah satu home industry yang memproduksi beraneka ragam kursi stool dan meja yang ada di Kota Blitar. Awalnya stool yang dihasilkan hanya dipakai sendiri dan sebagai hiasan rumah, namun karena bentuknya yang unik dan bernuansa shabby maka stool tersebut mulai dipesan oleh beberapa saudara dan teman yang berkunjung kerumah. Berdasarkan hal tersebut maka tujuan kegiatan pengabdian masyarakat ini adalah bagaimana merancang rebranding produk barokah meuble Blitar sebagai meuble penyedia kursi stool dan meja sudut yang berasal dari Kota Blitar Jawa Timur. Rebranding yang dilakukan pada Barokah Meubel Blitar adalah repositioning dan redesign. Untuk repositioning dilakukan melalui penciptaan image baru terhadap produk serta pengenalan identititas produk yang berbeda dari para kompetitor. Sedangkan pada tahap redesign tim akan melakukan desain ulang terhadap tampilan produk, jenis produk dan informasi produk. Sebagai evaluasi terhadap keberhasilan kegiatan yang telah dilakukan maka akan dilakukan juga evaluasi. Evaluasi yang dilakukan berupa prosentase kenaikan pemahaman dan informasi mengenai persiapan digital marketing yang telah dilakukan.
\end{abstract}

Kata kunci-rebranding, produk, repositioning, redesign.

\begin{abstract}
Barokah Meuble Blitar is one of the home industries that produce various stool chairs and tables in Blitar City. Initially, the stools produced were only used alone and as home decorations. However, because of their unique shape and shabby nuances, the stools began to be ordered by several relatives and friends who visited the house. Based on this, the purpose of this community service activity is how to design a rebranding of Blitar barokah furniture products as furniture providers for stool chairs and corner tables originating from Blitar City, East Java. The rebranding carried out on Barokah Furniture Blitar is repositioning and redesign. The repositioning is done by creating a new image of the product and introducing a product identity that is different from its competitors. Meanwhile, the team will redesign the product appearance, product type, and product information at the redesign stage. As an evaluation of the success of the activities carried out, an evaluation will also be carried out. The evaluation carried out is in the form of a percentage increase in understanding and information regarding digital marketing preparations that have been carried out.
\end{abstract}

Keyword-rebranding, product, repositioning, redesign.

\section{PENDAHULUAN}

Barokah meuble Blitar merupakan salah satu home industry yang memproduksi beraneka ragam kursi stool dan meja yang ada di Kota Blitar. Ibu Indah selaku pemilik memulai usaha meuble ini ketika terjadi lockdown di Malaysia, saat itu Ibu Indah memiliki usaha export buahbuahan dan makanan kaleng khas Indonesia. Namun karena pandemic dan ketatnya aturan yang diterapkan oleh pemerintahan Malaysia akhirnya semua kegiatan pengiriman dihentikan. Ide membuat stool ini bermula saat Ibu Indah beserta suami tanpa sengaja memikirkan bagaimana memanfaatkan limbah gendang, kardus bekas packing buah, serta triplek tidak terpakai yang

Submitted: Juli 2021, Accepted: Agustus 2021, Published: Agustus 2021

ISSN 2746-6345 (media online) 
berada dilingkungannya. Dengan dibantu oleh keempat anaknya yang browsing dan melihat beberapa tutorial di youtube akhirnya ibu Indah dan suami mencoba membuat kursi stool dari limbah-limbah tersebut. Awalnya stool yang dihasilkan hanya dipakai sendiri dan sebagai hiasan rumah, namun karena bentuknya yang unik dan bernuansa shabby maka stool tersebut mulai dipesan oleh beberapa saudara dan teman yang berkunjung kerumah.

Seiring berjalannya waktu, ternyata stool yang dihasilkan mendapatkan respon positif dan disenangi oleh konsumen. Berprinsip pada made by order yang tidak mengecewakan konsumen serta promosi dari mulut ke mulut membuat usaha ini terus berkembang. Promosi dari mulut ke mulut atau yang dikenal dengan personal selling ternyata mampu memberikan umpan balik yang secara tidak langsung dapat membuat hubungan interaktif antara konsumen dan penjual serta mengetahui minat pasar terhadap produk yang dijual(Astuti \& Saidah, 2020). Sejalan dengan hal tersebut penelitian dari (Mandasari et al., 2019) juga berpendapat bahwa penerapan promosi dari mulut ke mulut tidak hanya menerapkan konsumen sebagai pembeli tetapi juga berperan untuk meyakinkan konsumen lain terhadap kualitas dan kepuasan produk yang dihasilkan.

Selain menggunakan promosi dari mulut ke mulut, usaha meuble stool ini juga mulai mempromosikan produknya melalui media sosial seperti Instagram dan shoppe, namun sayangnya produk yang dipasarkan melalui keduanya masih bercampur dengan produk lainnya seperti produk kecantikan dan makanan yang merupakan usaha awal dari salah satu anak Ibu Indah. Ketika produk lokal seperti milik Ibu Indah dipasarkan melalui marketplace dapat menguntungkan pelaku industry local karena dapat mengurangi jumlah biaya dan waktu yang dikeluarkan dalam proses penjualan (Faridah \& Wulandari, 2020). Selain itu juga marketplace dapat mendorong pelaku usaha dalam mempromosikan produknya dan bertransaksi melalui internet secara maksimal(Sholeh et al., 2020).

Berdasarkan hal tersebut maka tujuan kegiatan pengabdian masyarakat ini adalah bagaimana merancang rebranding produk barokah meuble Blitar sebagai meuble penyedia kursi stool dan meja sudut yang berasal dari Kota Blitar Jawa Timur. Adapun solusi yang ditawarkan pada kegiatan ini adalah:

1. Perlu dilakukannya rebranding melalui pemisahanan produk melalui dibuatkannya kembali toko online yang secara khusus mempromosikan produk barokah meuble Blitar, baik di Instagram ataupun di shoppe.

2. Perlu dilakukannya pelatihan untuk tatacara promosi yang tepat baik dari sisi pengambilan foto produk yang professional, penulisan konten yang menarik di Instagram, facebook dan shopee dan berbagai kegiatan promosi lainnya.

Solusi pertama kami pilih karena untuk membangun konsep rebranding terhadap produk barokah meuble Blitar yang diharapkan dapat menciptakan suasana impulsive buying. Dimana impulse buying adalah suatu kegiatan pembelian yang tidak direncanakan sebelumnya saat konsumen melihat suatu produk yang dijual, namun dapat memberikan efek perasaan bahagia serta puas setelah melakukan pembelian (Trifiyanto, 2019), selain itu shopping lifestyle dan fashion involvement ternyata mempengaruhi impulse buying behavior (Fauziyyah \& Oktafani, 2018). Pada kegiatan ini impulsive buying yang akan digunakan adalah emosi konsumen seperti promosi dan keanekaragaman produk yang bernuansa shabby. Sedangkan untuk solusi kedua kami lakukan karena display produk pada toko online merupakan salah satu hal yang sangat penting, umumnya konsumen hanya membutuhkan deskripsi lengkap untuk produk yang akan dibelinya; foto yang menarik, jelas dan beresolusi tinggi sehingga mampu menampilkan detail produk; serta respon penjual yang cepat. Menurut penelitian (Iswati \& Maharani, 2019) penjualan melalui toko online sebaiknya lebih menekankan pada tampilan pada aplikasi, karena menurutnya ketika konsumen mudah dalam mengakses serta semakin bagus tampilan dan foto produk yang dihasilkan maka secara tidak langsung konsumen akan memiliki ketertarikan untuk membeli produk yang ditawarkan.

Melalui solusi yang ditawarkan, maka hasil akhir yang diharapkan pada kegiatan pengabdian masyakarat ini adalah dapat melakukan rebranding dan mendapatkan kepercayaan 
lebih besar lagi dari konsumen terhadap produk-produk barokah meuble Blitar melalui berbagai promosi yang tepat di media social untuk menaikkan jumlah penjualannya.

\section{METODE PELAKSANAAN}

Pada pelaksanaannya kegiatan pengabdian masyarakat ini diawali dengan pengumpulan informasi melalui wawancara dan observasi mengenai keadaan lokasi dan segala hal yang dibutuhkan oleh mitra kegiatan selama proses rebranding. Wawancara dilakukan untuk mendapatkan data yang sangat berpengaruh terhadap permasalahan yang dihadapi mitra (Anis Rohmadi, 2020). Setelah didapatkan data dan permasalahan, selanjutnya tim akan diskusi mengenai solusi dan tahapan dalam mencapai solusi tersebut serta manfaat yang akan dirasakan oleh lokus setelah dilakukannya kegiatan ini. Selanjutnya ide ini akan didiskusikan kepada mitra dengan tujuan memberikan gambaran dan persetujuan mitra. Sebelum melakukan rebranding terhadap produk, tim akan melakukan pelatihan terhadap pengambilan foto produk yang bagus, jelas dan memiliki nilai jual lebih saat ditampilkan di social media. Selain itu kami juga akan melakukan pelatihan terhadap proses editing foto agar foto produk semakin terlihat menarik tetapi tanpa merubah gambar asli. Setelah bahan didapatkan maka langkah selanjutnya adalah rebranding produk melalui pembuatan media social baru melalui Instagram, shoppe dan facebook. Rebranding yang dilakukan pada kegiatan ini hanya melakukan repositioning dan redesign produk untuk mendapatkan segemen pasar baru. Pada tahap akhir tim akan melakukan evaluasi terhadap solusi yang ditawarkan, manfaat dari evaluasi kegiatan menurut (Sofyan et al., 2020) adalah mengetahui manfaat dari solusi yang ditawarkan serta hambatan dan kekurangan yang terjadi. Rangkuman mengenai tahapan yang dilakukan terdapat pada Gambar 1.

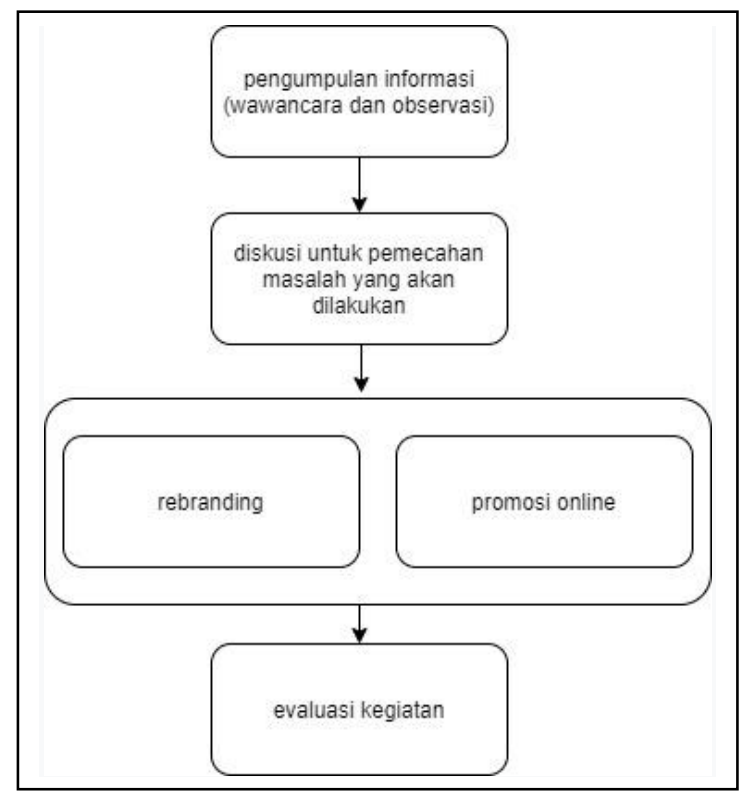

Gambar 1. Tahapan kegiatan

Berdasarkan tahapan kegiatan yang dilakukan maka indikator keberhasilan kegiatan ini kami rangkum pada Tabel 1. Sedangkan waktu pelaksanaan kegiatan ini selama 3 bulan terhitung bulan April sampai dengan Juni 2021.

Tabel 1. INDIKATOR KEBERHASILAN KEGIATAN

\begin{tabular}{|c|c|c|c|}
\hline Nomor & Permasalahan & Solusi & Hasil Capaian \\
\hline 1 & $\begin{array}{l}\text { Masih bercampurnya produk yang } \\
\begin{array}{ll}\text { ditawarkan dengan beberapa }\end{array}\end{array}$ & $\begin{array}{l}\text { Dilakukannya rebranding terhadap produk } \\
\text { melalui tahapan repositioning dan redesign }\end{array}$ & $\begin{array}{l}\text { Berhasil mendaftarkan barokah } \\
\text { meuble Blitar ke beberapa market }\end{array}$ \\
\hline
\end{tabular}




\begin{tabular}{|c|c|c|c|}
\hline Nomor & Permasalahan & Solusi & Hasil Capaian \\
\hline & produk lain. & $\begin{array}{l}\text { melalui pendaftaran di social media } \\
\text { (Instagram, shoppe, dan facebook). }\end{array}$ & $\begin{array}{l}\text { place dan social media yang telah } \\
\text { ditentukan. }\end{array}$ \\
\hline 2 & $\begin{array}{l}\text { Foto yang ditampilkan masih } \\
\text { sederhana. }\end{array}$ & $\begin{array}{l}\text { Perlu dilakukannya pelatihan dan promosi } \\
\text { yang tepat dari sisi pengambilan foto } \\
\text { produk yang professional, dan penulisan } \\
\text { konten yang menarik. }\end{array}$ & $\begin{array}{l}\text { Karyawan mampu melakukan } \\
\text { pengambilan foto yang menarik dan } \\
\text { mampu membuat konten menarik } \\
\text { untuk produk yang dijual. }\end{array}$ \\
\hline
\end{tabular}

\section{HASIL DAN PEMBAHASAN}

Pada tahapanan awal tim akan melakukan wawancara dengan pemilik untuk mengetahui kendala dalam memasarkan dan mendapatkan kepercayaan konsumen untuk produk yang dihasilkan. untuk mengetahui respon konsumen terhadap produk maka tim akan menyebar kuisioner tentang kepopuleran produk, ada tidaknya sentiment negative dari produk yang dihasilkan, laku tidaknya produk di masyarakat hingga jumlah competitor dengan produk yang sama. Berdasarkan hasil kuisioner yang didapatkan maka tim memutuskan untuk melakukan rebranding terhadap produk dengan tahapan repositioning yaitu menciptakan image baru terhadap produk yang dijual sehingga mendapatkan posisi baru dalam benak konsumen, competitor dan lainnya. Realiasasi dari kegiatan ini yaitu membuat suatu marketplace baru dengan nama "Barokah Furniture Blitar".

Untuk mendukung rebranding produk, tim akan melakukan pelatihan pemasaran digital melalui pengambilan produk, pengeditan produk serta penulisan konten untuk setiap produk yang akan dijual. Kegiatan ini akan dilakukan seminggu tiga kali selama dua bulan. Selain itu tim juga akan menjelaskan konsep dan alur dari program digital marketing yang akan dilaksanakan guna mengoptimalkan pemasaran. Realisasi dari kegiatan ini terlihat pada Gambar 2 dan 3.

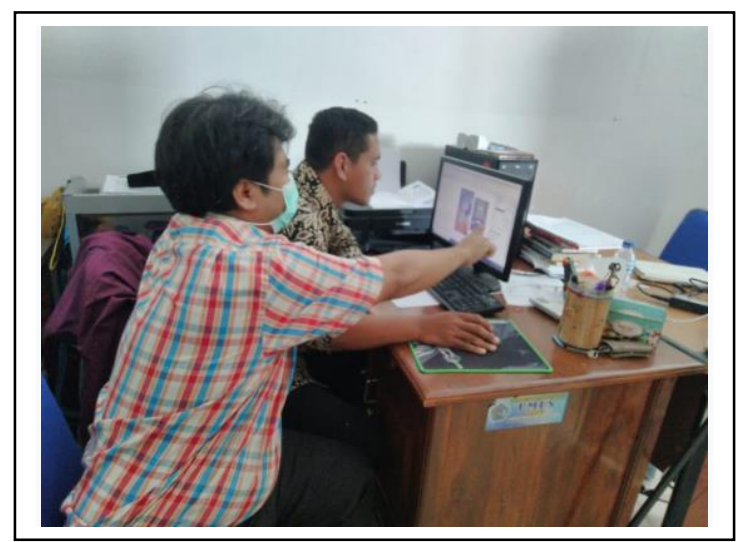

Gambar 2. Pelatihan pengeditan foto produk

Pada gambar 2, pelatihan akan dilakukan kepada karyawan paling muda. Hal ini disebabkan karena anak muda biasanya memiliki kreatifitas yang lebih baik bila dibandingkan dengan karyawan yang lebih dewasa. 


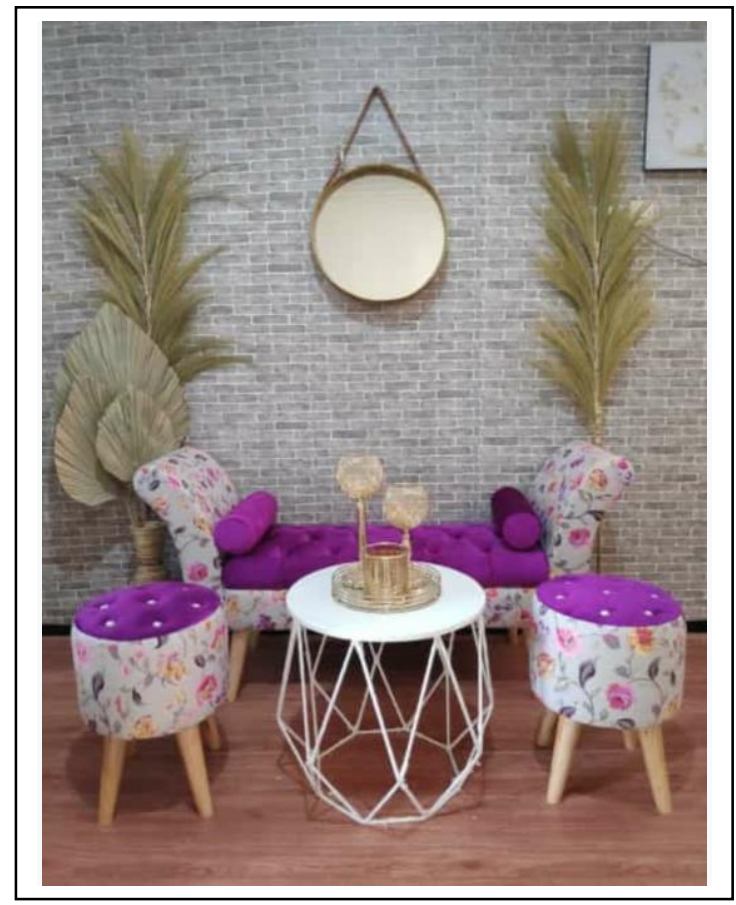

Gambar 3. Pelatihan pengeditan foto produk

Gambar 3 merupakan gambar hasil edited foto dengan menggunakan coreldraw. Tim tidak akan merubah warna asli pada produk tetapi lebih kepada penajaman warna serta perubahan background agar lebih menarik. Untuk mendukung agar rebranding produk lebih melekat kepada konsumen maka tim juga membuatkan logo yang akan disematkan pada produk yang akan dipasarkan. Gambar 4 merupakan logo yang akan digunakan.

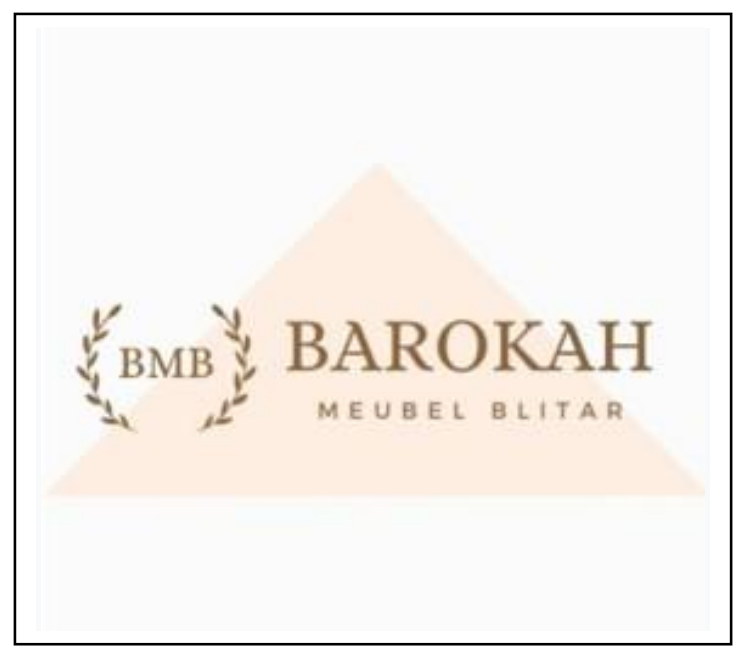

Gambar 4. Logo produk

Hasil akhir yang akan diperoleh oleh mitra ketika foto produk, logo dan informasi mengenai produk dijadikan satu gambar, maka akan terlihat seperti Gambar 5. Melalui gambar 5, informasi mengenai produk telah diinfokan secara jelas mulai dari ukuran meja dan stool, variasi warna besi meja, serta warna dan motif dari stool yang tersedia. 


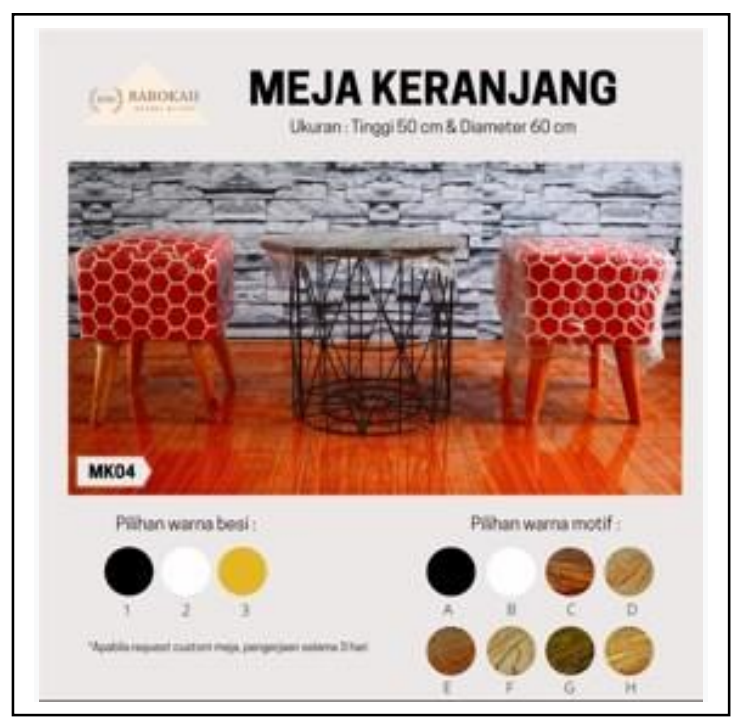

Gambar 5. Foto final produk yang akan dipasarkan

Untuk mendapatkan masukan dari mitra, maka tim akan melakukan evaluasi terhadap kegiatan yang telah dilakukan. Kegiatan ini berupa tanggapan mitra terhadap pelatihan desain yang telah dilakukan, penulisan konten dan jumlah penjualan. Gambar 6 adalah rangkuman hasil evaluasi yang dilakukan.

Dari gambar 6 diketahui bahwa pemahaman akan pengambilan gambar suatu produk bagi karyawan akan meningkat $45 \%$ setalah dilakukannya pelatihan oleh tim, dampaknya foto produk akan lebih menarik, stabil (tidak blur karena goyang dan tidak terlalu berlebihan). Selain itu karyawan juga mulai memperhitungkan tampilan produk agar lebih instagramable agar produk yang dipasarkan tidak terkesan seadanya tetapi mampu menarik minat dan keinginantahuan konsumen terhadap produk. Prosentase terhadap cara memasarkan produk yang instagramable juga jauh lebih meningkat yaitu naik menjadi $85 \%$ dari $25 \%$. Sedangkan untuk tatacara penulisan konten, juga mengalami kenaikan yang cukup signifikan dimana konten dan informasi produk ternyata tidak pelu ditulis diluar gambar produk, tetapi dapat menjadi satu dengan foto produk dengan layout yang tepat. Pemahaman tentang hal ini juga mengalami peningkatan yang cukup signifikan yaitu $60 \%$.

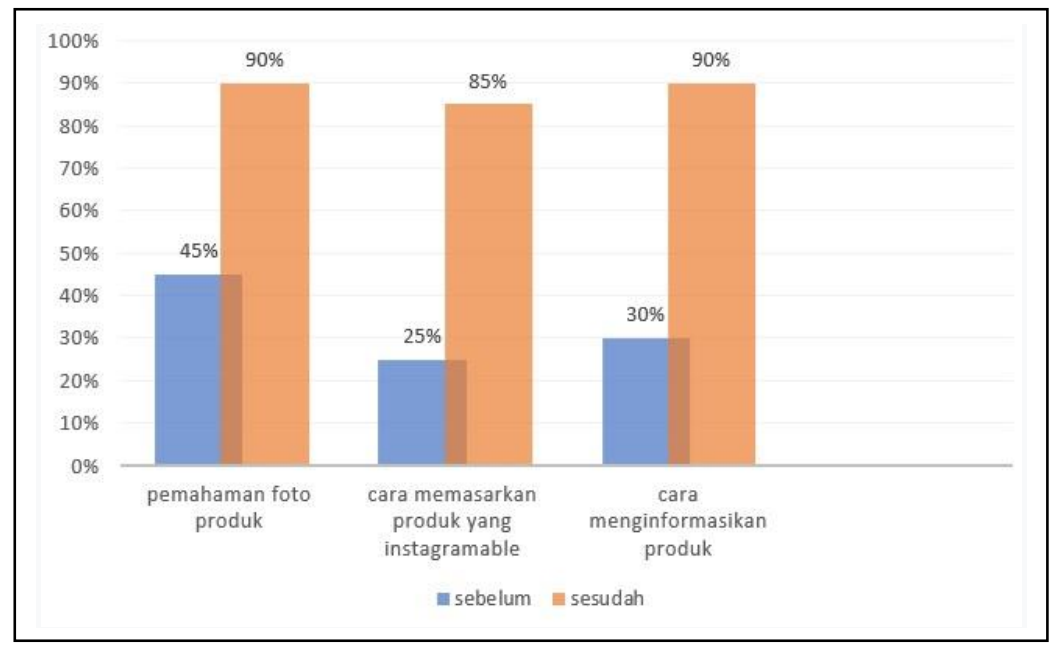

Gambar 6. Evaluasi solusi kegiatan 


\section{KESIMPULAN}

Berdasarkan hasil kegiatan, diketahui bahwa rebranding produk ternyata mampu menciptakan image baru produk baik dari sisi penjualan ataupun tingkat kepercayaan konsumen. Rebranding yang dilakukan pada Barokah Meubel Blitar adalah repositioning dan redesign. Untuk repositioning dilakukan melalui penciptaan image baru terhadap produk serta pengenalan identititas produk yang berbeda dari para kompetitor. Sedangkan pada tahap redesign tim akan melakukan desain ulang terhadap tampilan produk, jenis produk dan informasi produk. Sebagai evaluasi terhadap keberhasilan kegiatan yang telah dilakukan maka akan dilakukan juga evaluasi. Evaluasi yang dilakukan berupa prosentase kenaikan pemahaman dan informasi mengenai persiapan digital marketing yang telah dilakukan. Sedangkan untuk pemantauan jumlah kenaikan pemesanan tidak dilakukan karena efektifitas rebranding memerlukan waktu minimal satu tahan dari proses launcing branding baru.

\section{DAFTAR PUSTAKA}

Anis Rohmadi, V. Y. (2020). Desain dan Penerapan Website Tata Kelola Percetakan Pada CV APICDESIGN KREASINDO JAKARTA dengan Metodey Prototyping. Journal of Information System, Infomatics and Computing, 4(1), 70-85.

Astuti, R., \& Saidah, I. (2020). Strategi Promosi Produk Fashion Pada Usaha Mikro Kecil Menengah ( UMKM ) di Kota Bandung. Textura Journal, 1(1), 78-87.

Faridah, F., \& Wulandari, Z. W. (2020). Pendampingan Pemasaran Industri Lokal Melalui Penggunaan Marketplace untuk Meningkatkan Hasil Produksi di Masa Pandemi Covid-19 Desa Sidomukti Lamongan. Engagement: Jurnal Pengabdian Kepada Masyarakat, 4(2), 509-523. https://doi.org/10.29062/engagement.v4i2.316

Fauziyyah, A. N., \& Oktafani, F. (2018). Pengaruh Shopping Lifestyle Dan Fashion Involvement Terhadap Impulse Buying Behavior (Studi pada Masyarakat Kota Bandung). Jurnal Riset Bisnis Dan Manajemen, 8(1), 1-14.

Iswati, H., \& Maharani, N. (2019). Perbedaan Display Toko Offline dan Toko Online Untuk Produk Pakaian Wanita. Jurnal Manajemen Dan Bisnis Performa, 16(2), 100-112. https://doi.org/10.29313/performa.v16i2.4880

Mandasari, D. J., Widodo, J., \& Djaja, S. (2019). Strategi Pemasaran Usaha Mikro, Kecil dan Menengah (UMKM) Batik Magenda Tamanan Kabupaten Bondowoso. Jurnal Pendidikan Ekonomi, 13(1), 123-128. https://doi.org/10.19184/jpe.v13i1.10432

Sholeh, M., Triyono, J., \& Rachmawati, R. Y. (2020). Pendampingan Kelompok Informasi Masyarakat Dengan Memanfaatkan Marketplace Sebagai Media Pemasaran. Jurnal Penelitian Dan Pengabdian Kepada Masyarakat UNSIQ, 7(2), 158-164. https://doi.org/10.32699/ppkm.v7i2.965

Sofyan, S., Setiyadi, B., Harlina Harja, \& Sari, S. R. (2020). Pelatihan Penyusunan Tata Kerja Dan Analisis Evaluasi Program Kegiatan Sekolah. BERNAS: Jurnal Pengabdian Kepada Masyarakat, 1(4), 417-425. https://doi.org/10.31949/jb.v1i4.465

Trifiyanto, K. (2019). Pengaruh Dimensi Online Visual Merchandising dan Promosi Penjualan Online Terhadap Impulse Buying. Jurnal Hummansi, 2(September), 29-37. https://doi.org/10.33488/1.jh.2019.2.213 